\title{
MACHINING CONDITIONS IMPACT ON THE FATIGUE LIFE OF WASPALOY - IMPACT OF GRAIN SIZE
}

\author{
Nihad Ben Salah ${ }^{1}$, Serafettin Engin ${ }^{2}$ \\ Pratt \& Whitney Canada; \\ 1000 Marie Victorin 01HC4; Longueuil; QC; J4V 2K3, Canada \\ ${ }^{1}$ Materials engineering \\ ${ }^{2}$ Manufacturing Engineering
}

Key words: Waspaloy; Broaching, Near-surface microstructure, Low-cycle fatigue

\begin{abstract}
To assess the severity of a machining process and its impact on the integrity of engine turbine disk, near-surface microstructure (NSM) is usually an indicator. Waspaloy was machined by broaching with different severities (mild, aggressive and very aggressive), tested and compared with low-stress ground material. This work has shown that for Waspaloy, even though the NSM is a good indicator of the severity of the broaching process, it is not necessarily a good predictor of the resultant low -cycle fatigue (LCF) life. Waspaloy displayed a fatigue life dependent on grain size. ASTM4 and ASTM7 material showed different fatigue behavior. Fatigue life of large grain (LG) Waspaloy improves when the material is mildly broached compared to low-stress grinding, while fine grain (FG) material does not see improvement unless the broaching is more aggressive. For LG, suppression of supergrains by mild broaching may be the cause of increasing life, while for FG aggressively broached; surface compressive residual stresses may be the driver. When the broaching is very aggressive, causing the formation of a highly distorted surface layer, none of these phenomena seems to occur and the fatigue life of the material decreases significantly.
\end{abstract}

\section{Introduction}

Nickel-based superalloys are extensively used for rotating components in the hot sections of turbine engines. Waspaloy is used whenever mechanical properties stability is needed at elevated temperature. Several machining processes are used for the production of engine components. More specifically, broaching is used to achieve complicated geometry. It is known that nickel-based superalloys are very sensitive to microstructure distortions during machining. Localized thermo-mechanical work occurs and the near surface microstructure may change [1-8]. Consequently, the mechanical properties are adversely affected $[9,10]$. The effect of this change on the mechanical properties of the component, is not fully understood, however since the fatigue behavior strongly depends on surface properties, it is expected that the fatigue life of component may be affected.

The objective of the present paper is to determine how plastic deformation of the surface by machining could affect the low-cycle fatigue life of Waspaloy. Different deformation severities are produced by broaching at different conditions. Their impact on the near surface 
microstructure (NSM) of Waspaloy and consequently its notch low cycle fatigue (LCF) life at high temperature $\left(593^{\circ} \mathrm{C}\right)$ is investigated. The grain size factor was addressed here to determine its impact on the material behavior during machining and thus, on the fatigue life. This work has focused mainly on crack initiation sites observed by SEM on ruptured fatigue specimens and near-surface microstructure and was supplemented with nanohardness measurements to assess the microstructure changes.

\section{Experimental methods}

\section{$\underline{\text { Material }}$}

Material used in this study was hot rolled Waspaloy nickel-base superalloy. The nominal chemistry of the specific alloy (wt \%) was $1.4 \% \mathrm{Al}, 4 \% \mathrm{Mo}, 3 \% \mathrm{Ti}, 19.5 \% \mathrm{Cr}, 13.5 \% \mathrm{Co}, 0.07$ $\% \mathrm{Zr}, 0.05 \% \mathrm{C}, 0.06 \% \mathrm{~B}$, and balance $\mathrm{Ni}$. The specimens were extracted from a fully processed $8.25 \mathrm{~cm}$ bar that was given a conventional $1021^{\circ} \mathrm{C}$ sub-solvus solution treatment followed by a sequence of two-step ageing at $843^{\circ} \mathrm{C}$ and $760^{\circ} \mathrm{C}$. This process cycle resulted in $\gamma^{\prime}$ precipitates in bulk $\gamma$ structure with hardness of approximately $380 \mathrm{HB}$. A typical microstructure viewed in light microscope is shown in Fig. 1 in which only the $\gamma$ matrix equiaxed grains are observed. Two sets of grain-size were tested. For large grains, more than $90 \%$ of the grains are finer than $84 \mu \mathrm{m}$ (ASTM 4) with less than 10\% grains larger than ASTM 3 (about 154 $\mu \mathrm{m}$ ). Small grains are finer than $36 \mu \mathrm{m}$ (ASTM 7) with 5\% of ASTM 4 grains. The two sets were taken from the same $8.25 \mathrm{~cm}$ diameter bar. Small grains were from the outside and larger grains were from the core of the bar, thus the grain size impact could be assessed without the chemistry variation. It is worth noting that grain size was determined on selected specimens from the two areas and verified on fatigue specimens.

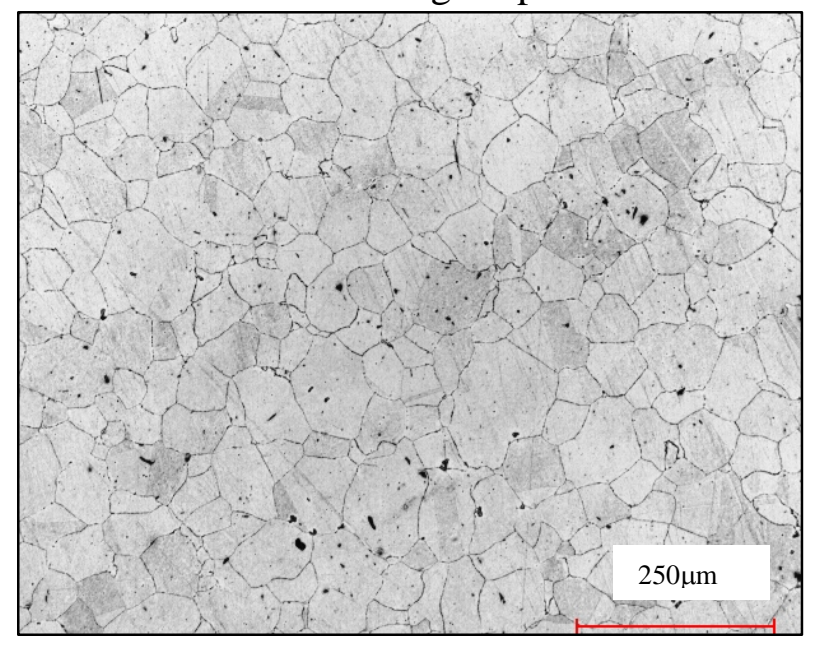

a) Grain size ASTM 4

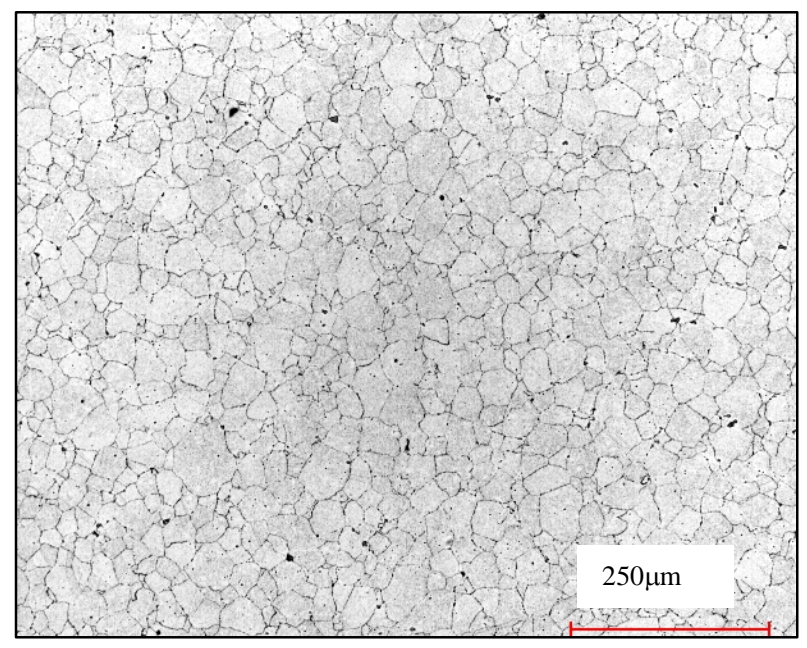

b) Grain size ASTM 7

Figure 1. Light microscope image of Waspaloy (Kalling's etchant) a) ASTM 4 b) ASTM 7

\section{$\underline{\text { Low-cycle fatigue test conditions }}$}

A double-side notch specimen was designed for the test. The $7.62 \mathrm{~cm}$ long specimen has a rectangular gage section of nominal dimensions $1.9 \mathrm{~cm} \times 0.91 \mathrm{~cm} \times 0.635 \mathrm{~cm}$. The round- 
shaped notch feature was introduced on the both sides of the gage by machining the slots that produced a stress concentration factor $\left(\mathrm{K}_{\mathrm{t}}\right)$ of 2.26 during axial low-cycle fatigue (LCF) loading of the specimen. Besides the effect of $\mathrm{K}_{\mathrm{t}}$, the near-surface condition of the slots was important in influencing the LCF life.

The notches were machined using the processes to be tested i.e. broaching with different severities and the baseline process, which is low-stress grinding (LSG). Except for LSG where the notches were polished after machining, for all other processes the notches were tested as machined. After notch insertion using the tool shown in Figure 2, hand edge break was done to avoid crack initiation at the edges. Testing was conducted at temperature of $593^{\circ} \mathrm{C}$ and notch root 'concentrated' (cc) stress of $1793 \mathrm{MPa}$ using a servo-hydraulic machine. These conditions simulate the extreme operation conditions in some areas of the turbine disks. Tests were performed using triangular waveform loading under stress ratio $(\mathrm{R})$ of 0.05 and test frequencies of $0.17 \mathrm{~Hz}$. Fatigue point data for each set of conditions were analyzed using the best fitted probability distribution, which allows to draw probability plots and determine the distribution parameters useful to compare the different populations and assess the impact of the machining severity and the grain size. Fractured LCF specimens were subjected to micro-fractography analysis to document the crack initiation sites, as well as metallographic evaluation in the sections perpendicular to the fracture surface near the fracture origin in order to determine the correspondent near-surface microstructure.

\section{$\underline{\text { Tools and machining conditions investigated }}$}

The influence of machining conditions was assessed by machining the notch on the LCF specimens using three different broaching conditions against the low-stress grinding (LSG) condition which is supposed to be the machining condition that provides the best near surface microstructure. The notch surface produced by LSG is polished afterward in order to produce lines parallel to the loading direction.

The three different broaching conditions are identified as: Mild broaching, aggressive broaching and very aggressive broaching. The parameters to produce these three conditions are defined below.

The same single-round cutting edge tool geometry with different rake angle and edge preparations has been used for all the tests in this study. P/M T15 tool steel tool with one cutting edge has been used to control the chip load by the machine tool controller. Tool geometry $t$ is given in Figure 2.

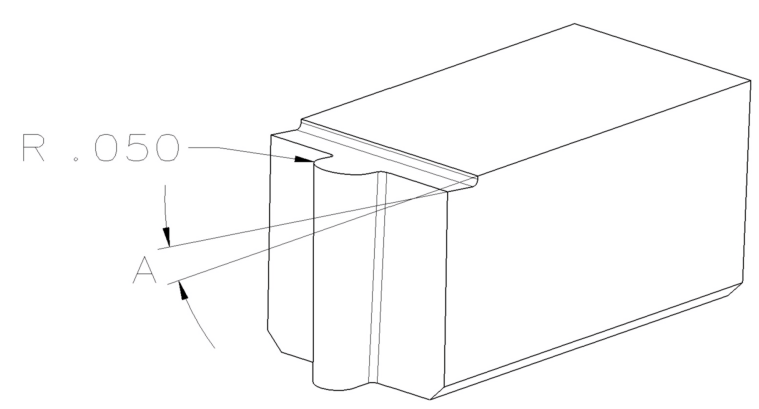

Figure 2. Broaching tool geometry used to machine the specimens notch with $1.27 \mathrm{~mm}$ radius. A is the rake angle. 
The cutting edge conditions have been created to simulate tool cutting edge wear and produce three categories: mild, aggressive and very aggressive cutting conditions as shown in table 1. Cutting speed was maintained for all conditions at 3 to $4 \mathrm{~m} / \mathrm{min}$..

Table 1: Cutting conditions

\begin{tabular}{|l|c|l|c|c|}
\hline $\begin{array}{l}\text { Condition } \\
\text { category }\end{array}$ & $\begin{array}{c}\text { Rake Angle } \\
\text { [degree] }\end{array}$ & \multicolumn{1}{|c|}{$\begin{array}{c}\text { Cutting edge } \\
\text { Preparation }\end{array}$} & $\begin{array}{c}\text { Chip } \\
\text { load } \\
{[\mathbf{m m}]}\end{array}$ & $\begin{array}{c}\text { Cutting Oil type } \\
\text { and direction }\end{array}$ \\
\hline $\begin{array}{l}\text { Mild } \\
\text { Aggressive }\end{array}$ & +14 & Sharp & 0.0127 & Flooding \\
Very & -2 & Sand blasted 1 min. & 0.0127 & Wet* \\
Aggressive & -10 & Spindle deburr $2 \mathrm{~min}$. & 0.0127 & Wet* $^{*}$ \\
\hline
\end{tabular}

* The cutting area has left wet at the beginning of the cut without supplying cutting fluid through out the cutting process

Tool wear resulting from the different broaching conditions

The cutting edge wear of the tools after notch machining as defined in Table 1 is shown in Figure 3 and Figure 4.

Slight tool wear after notch machining has been observed for the mild cutting condition (Figure 3 ) due to the large rake angle $\left(+14^{\circ}\right)$ and flooding cutting fluid that made the shearing process easy and with low friction. More tool wear has been observed for the aggressive condition (Figure 4a) where a slight material transfer from the work piece was found. Significant tool wear has been observed for the very aggressive cutting condition (Figure $4 \mathrm{~b}$ ) with a significant transfer from the work piece.

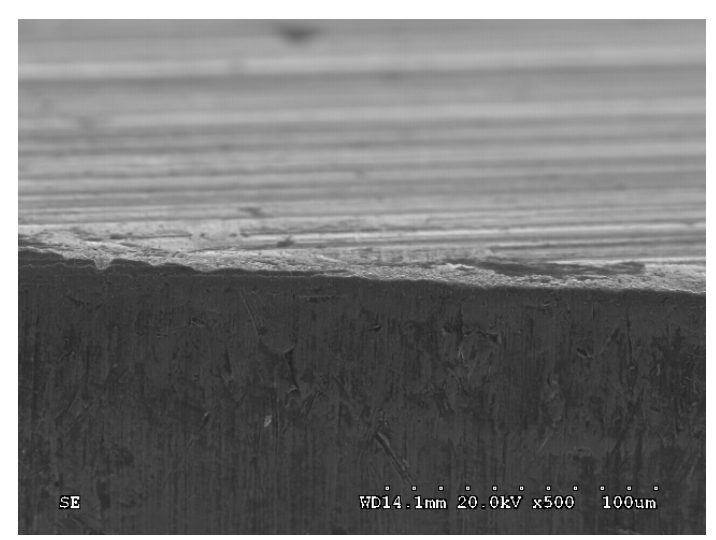

Figure 3. Tool cutting edge wear after mild broaching $\left(+14^{\circ}\right.$ rake angle, sharp cutting), SEM 

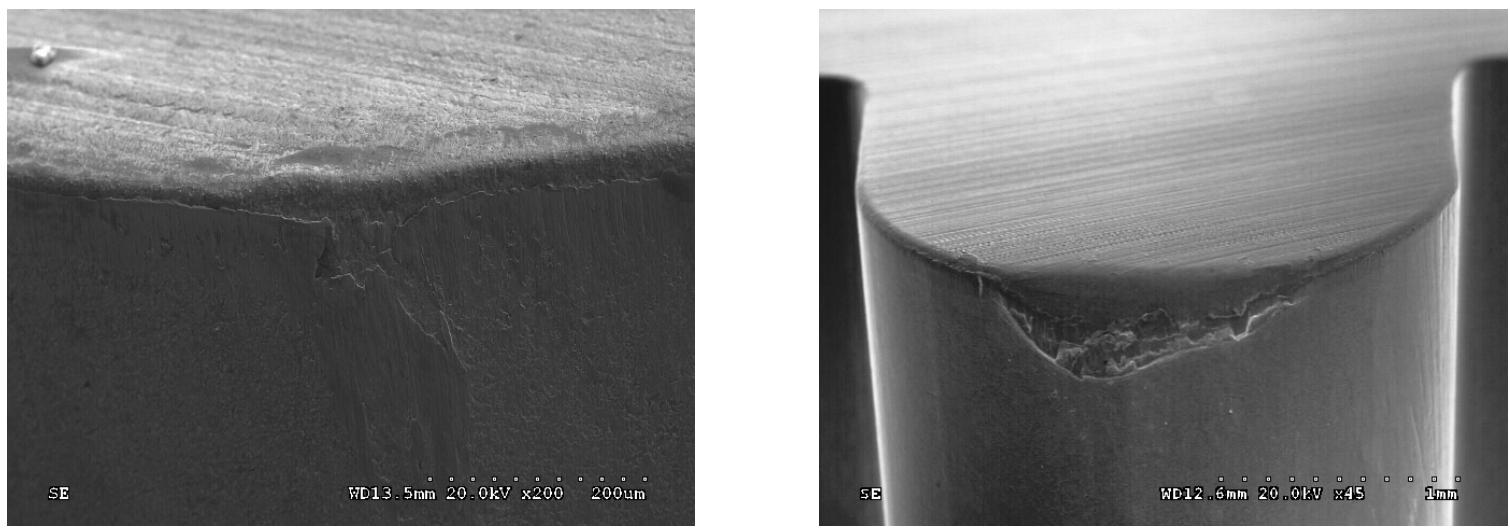

Figure 4. Tool cutting edge wear after a) aggressive broaching $\left(-2^{\circ}\right.$ rake angle, cutting edge rounded by sand blasted) b) very aggressive broaching $\left(-10^{\circ}\right.$ rake angle, cutting edge rounded by spindle deburr), SEM

\section{Characterization methods}

The near surface microstructure (NSM) was documented on transverse sections at the notches, perpendicular to broaching direction. Specimens were mounted, polished, and etched using Kalling reagent.

SEM coupled with EDX analysis was used to observe and analyze crack surfaces.

Nanohardness, $H_{N}$, the reduced Young's modulus, $E_{r}$, and their lateral distributions were determined by depth-sensing indentation using the Nano-triboindenter instrument (Hysitron Inc.) equipped with a Berkovich pyramidal indenter in agreement with the International Standard [11]. The technique developed by Oliver and Pharr [12] is used to determine the surface mechanical properties changes after machining.

\section{Results}

\section{$\underline{\text { Notched Low Cycle Fatigue }}$}

Notch LCF tests have shown that fine (ASTM 7) and large grains (ASTM 4) exhibit different fatigue lives at the temperature and stress used $\left(593^{\circ} \mathrm{C} / 1793 \mathrm{MPa}\right.$ concentrated $)$. The notch strength ratio of Waspaloy at the test temperature which is the ratio between the notch strength and the smooth strength of the material was found in another study to be higher than one [13]. This indicates that Waspaloy is not notch sensitive for the Kt and the temperature used. The plasticization in the notch root induces hardening not softening of the material.

Probability plots were drawn to visualize the impact of the machining process on the fatigue life of the two grain size materials. For all plots, lognormal regression was found to fit the best the data. Low-stress ground surface is considered the reference condition to which all surfaces were compared. The normalized life is the ratio of actual life and the B0.1 life of the low-stress ground fine-grain material.

It is against this condition that the broaching with different severities was compared. 
The probability plot of Figure 5 for the low-stress grinding condition indicates that the fine grain has a better life than the large grain material but with a larger scatter.

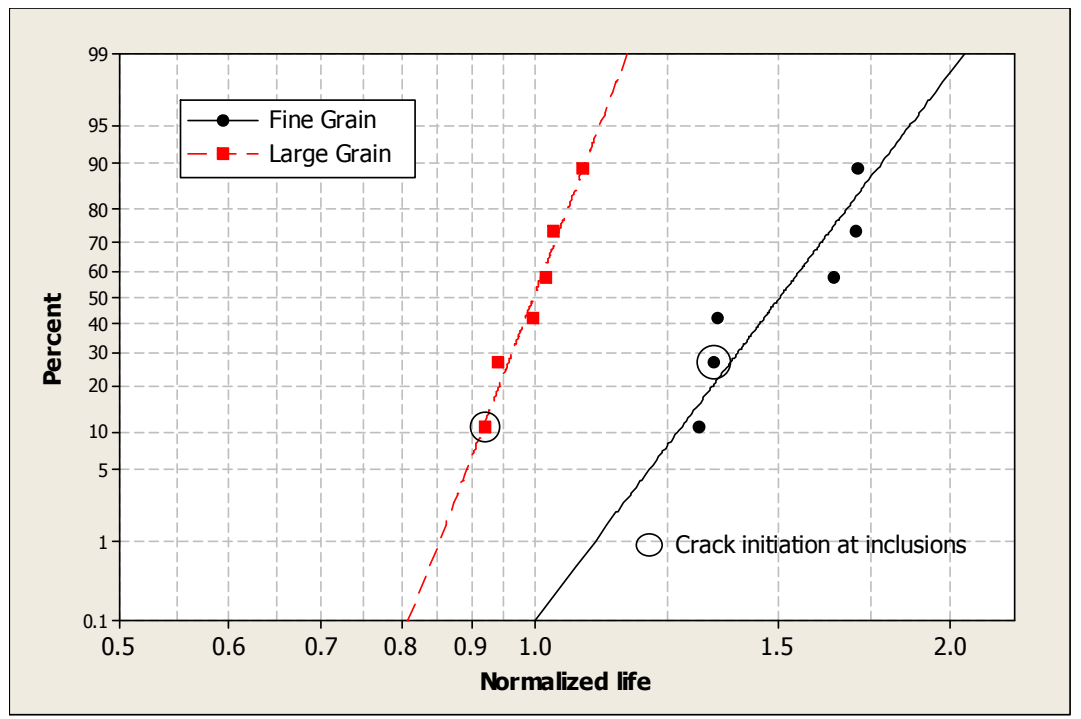

Figure 5. Probability plot for the low-stress grinding condition showing the difference in fatigue life between large and fine grain Waspaloy

Broaching seems to introduce an important scatter in fatigue life whatever are the conditions and the grain size.

However, the life classification does not follow the severity of the broaching, and is different depending on the grain size. Probability plots shown in Figure 6 and Figure 7 illustrate this finding.

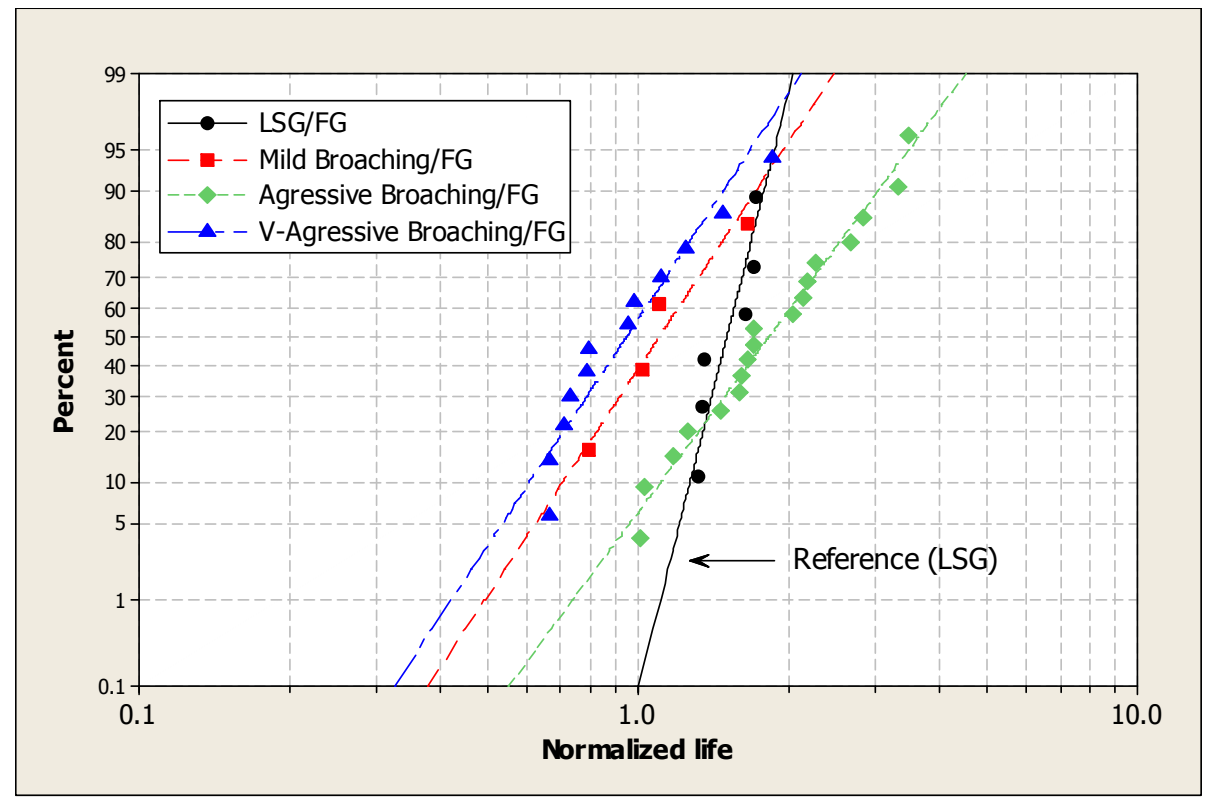

Figure 6. Probability plot showing the notch LCF life of fine grain Waspaloy for the three broaching conditions against low-stress grinding 


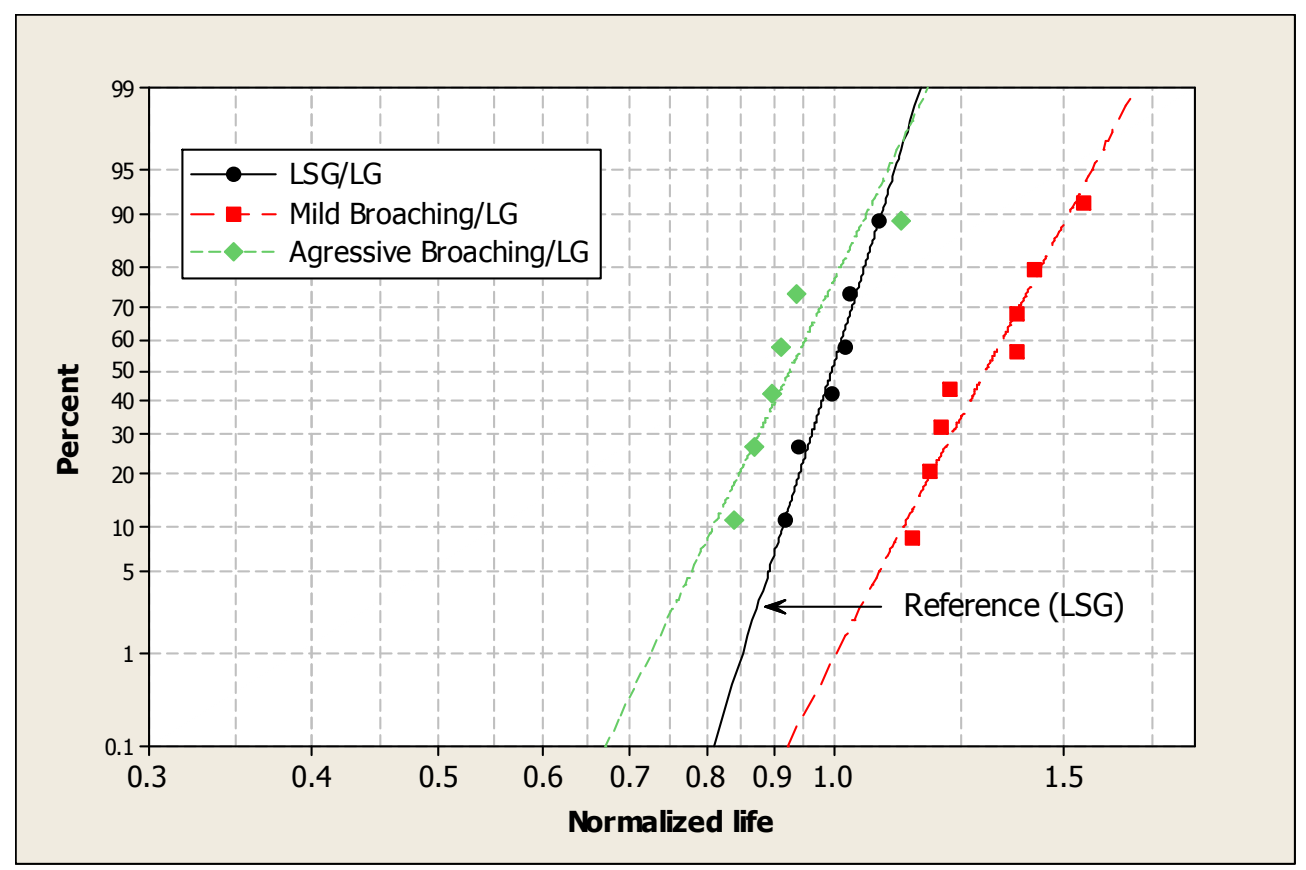

Figure 7. Probability plot showing the notch LCF life of large grain Waspaloy for the three broaching conditions against low-stress grinding

Mild broaching induces a lower life than low-stress grinding for the FG material.

In addition, low-stress grinding that is assumed to be the machining condition that introduces the least surface damage, does not provide the best typical fatigue life for the two grain sizes.

More surprisingly, for the fine grain material, the best life is obtained for aggressive broaching. Fatigue life debit linked to the grain size is also affected by the broaching severity. The large grain Waspaloy that shows a lower life compared to the fine grain (Figure 5) has a better life after mild broaching but then loses it when the broaching is severe (Table 2).

Table 2. Fatigue life debit associated to the grain size for each machining process

\begin{tabular}{|l|c|}
\hline Process & GS typical life debit (LG Vs FG) \\
\hline LSG & 1.51 \\
Mild Broaching & 0.84 \\
Aggressive Broaching & 1.81 \\
\hline
\end{tabular}

\section{$\underline{\text { LCF crack initiation sites and correspondent near-surface microstructure }}$}

Near-surface microstructure

The near-surface microstructures (NSM) near the crack surfaces after failure were observed for each machining condition.

Table 3 gives the extent of the grain distortion as well as the depth of the severely deformed layer for each machining condition. These data were determined close to the crack initiation site (CIS). 
Table 3. Depth of severely deformed layer and grain distortion for the different machining conditions as produced on fatigue specimens

\begin{tabular}{|l|c|c|}
\hline \multicolumn{1}{|c|}{ Process } & $\begin{array}{c}\text { Severe deformation* } \\
\mu \mathrm{m}\end{array}$ & $\begin{array}{c}\text { Grain Distrortion } \\
\mu \mathrm{m}\end{array}$ \\
\hline LSG & 0 & 0 \\
Mild Broaching & 0 & $4-13$ \\
Agressive Broaching & $2-5$ & $10-23$ \\
Very Agressive Broaching & $4-10$ & $18-33$ \\
\hline
\end{tabular}

* Surface layer where the grain boundaries are no more defined

In absence of machining damage, i.e. for LSG, near surface microstructure (NSM) of Waspaloy is as shown in Figure 8. FG and LG material show similar NSM. No grain deformation is observed.

The NSM resulting from the broaching conditions are given in Figure 8 through Figure 11. As expected, the severity of grain distortion produced by broaching increases when the broaching is more aggressive. It is worth noting that very aggressive broaching was tested on the FG only. For the LG, very aggressive broaching was not tested since aggressive broaching seemed to be the threshold at which the fatigue properties decrease.
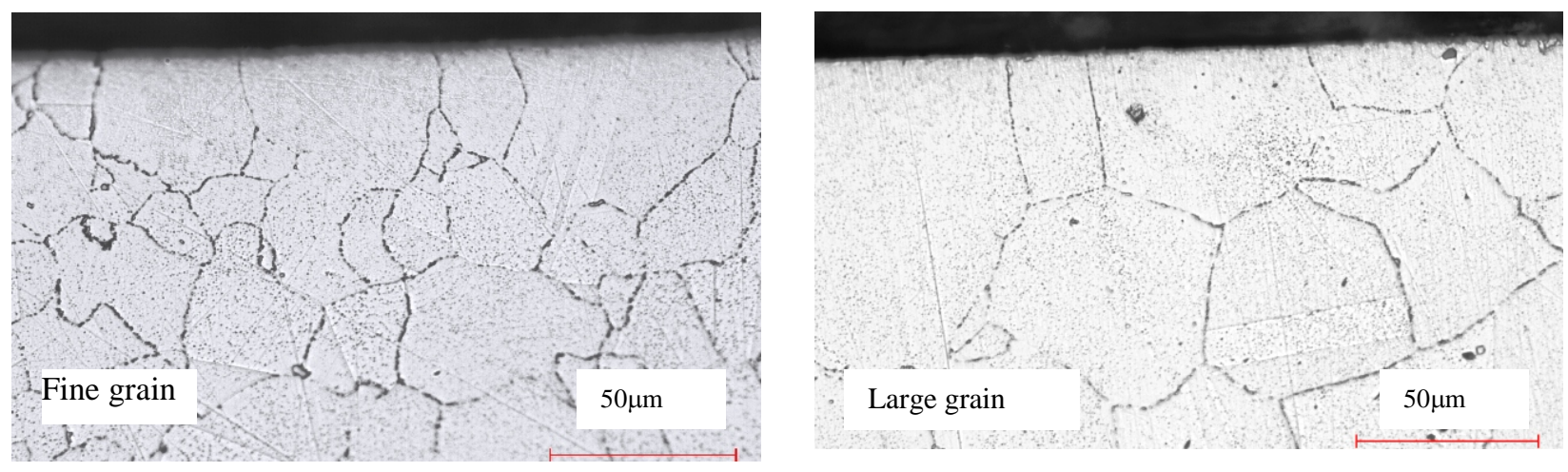

Figure 8. NSM of fine-grain and large grain Waspaloy after low-stress grinding

Mild broaching produced the least distorted NSM (Figure 9). No difference was observed between the FG and LG material NSM, even though LG material has a better fatigue life than FG inversing the tendency observed on the low-stress ground material.

NSM produced by aggressive broaching show similar grain deformation for both FG and LG (Figure 10).

The most affected NSM was that obtained by very aggressive broaching (Figure 11), where a severely deformed near-surface layer is created. In this layer the severity of the deformation is such that grain boundaries are no more revealed by etching. It was shown that this type of layer has a different reaction to etch because it has a microstructure and chemistry different from the bulk. These layers produced by machining are found to be nano-crystalline and usually rich in oxygen resulting from a reaction of the material with the environment $[14,15]$. 


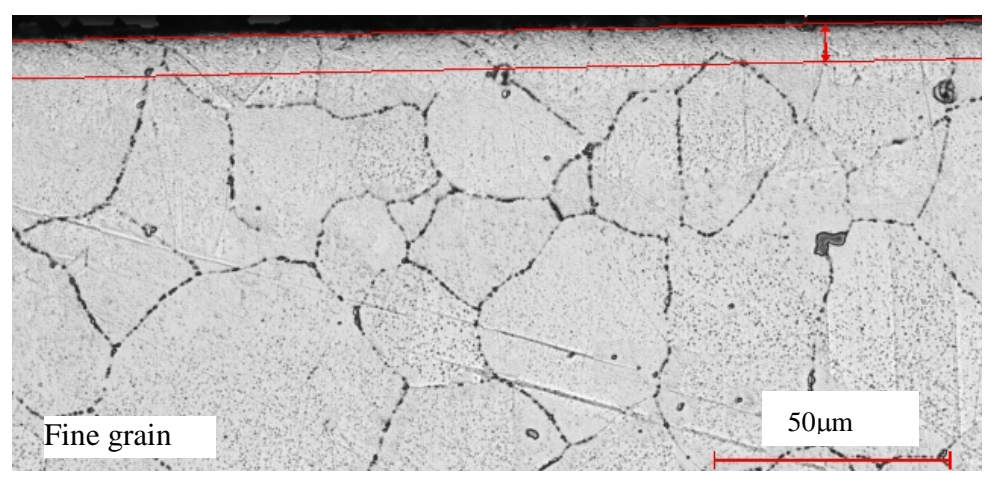

Figure 9. Typical NSM after mild broaching, fine-grain Waspaloy

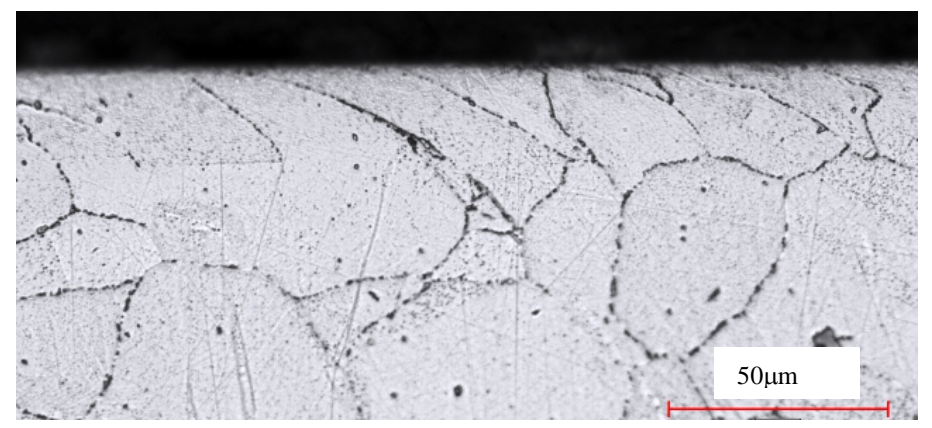

a) Fine grain

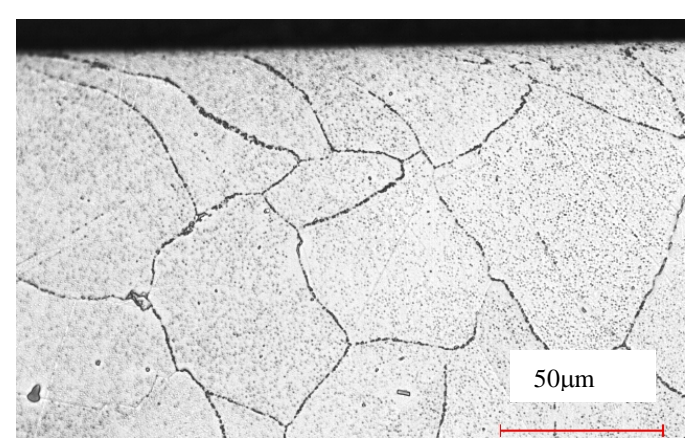

b) Large grain

Figure 10. Aggressive broaching NSM (Kalling's etchant) in a) fine grain material, b) large grain material
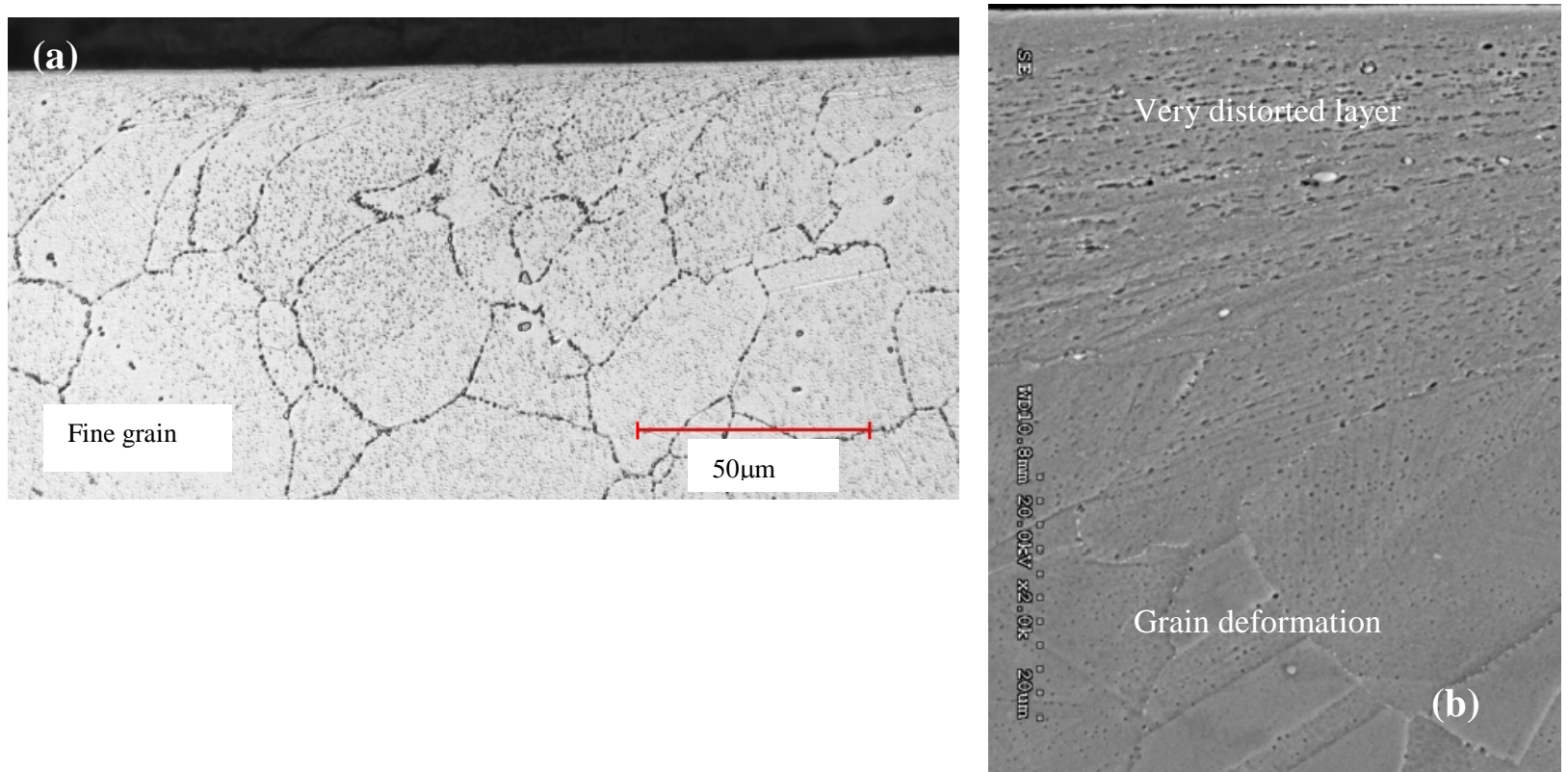

Figure 11. Very aggressive broaching NSM (Kalling's etchant) in fine grain material showing the very distorted layer and the grain deformation depth a) Optical microscopy b) SEM 


\section{Fatigue crack initiation sites}

Typical fatigue crack initiation sites (CIS) that occurred in the notch of specimens machined by the different broaching conditions are shown in Figure 12 through Figure 15. Macrographs of the crack surface are given in the bottom-left of each picture.

The macrographs show typically 3 areas; white spots at the crack initiation sites that appear white in the stereo-microscope because of the flatness of these areas, a blue area that corresponds to the crack propagation, and a dark area which is the rough overload area.

The main CIS in Waspaloy machined by LSG are large surface grains. Lower lives are often associated with Ti-rich carbides or nitrides (Figure 12).

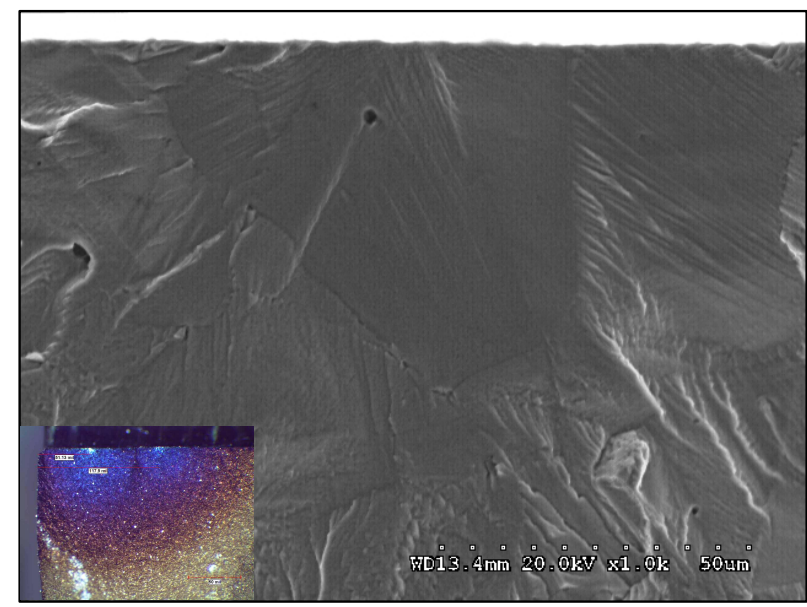

a) Fine grain Waspaloy

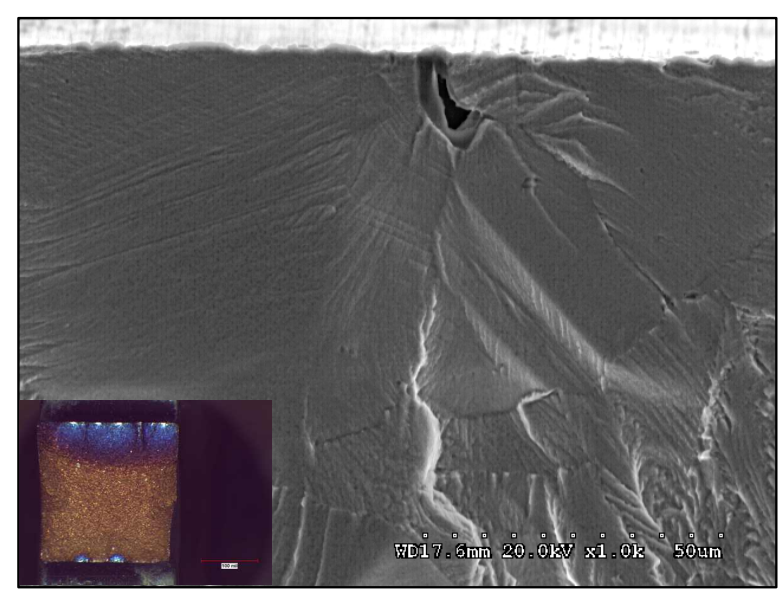

b) Large grain Waspaloy

Figure 12. Crack surface observed in SEM of Waspaloy for low-stress grinding showing typical crack initiation a) from large grain b) From Ti-rich inclusion - Crack surface macrograph at the corner showing CIS location

After mild broaching, the same CIS as observed for LSG are observed for large grain size Waspaloy. However, for the fine grain, crack initiation is more diffuse encompassing several grains where deformation lines crossing the grain boundaries were observed (Figure 13). 

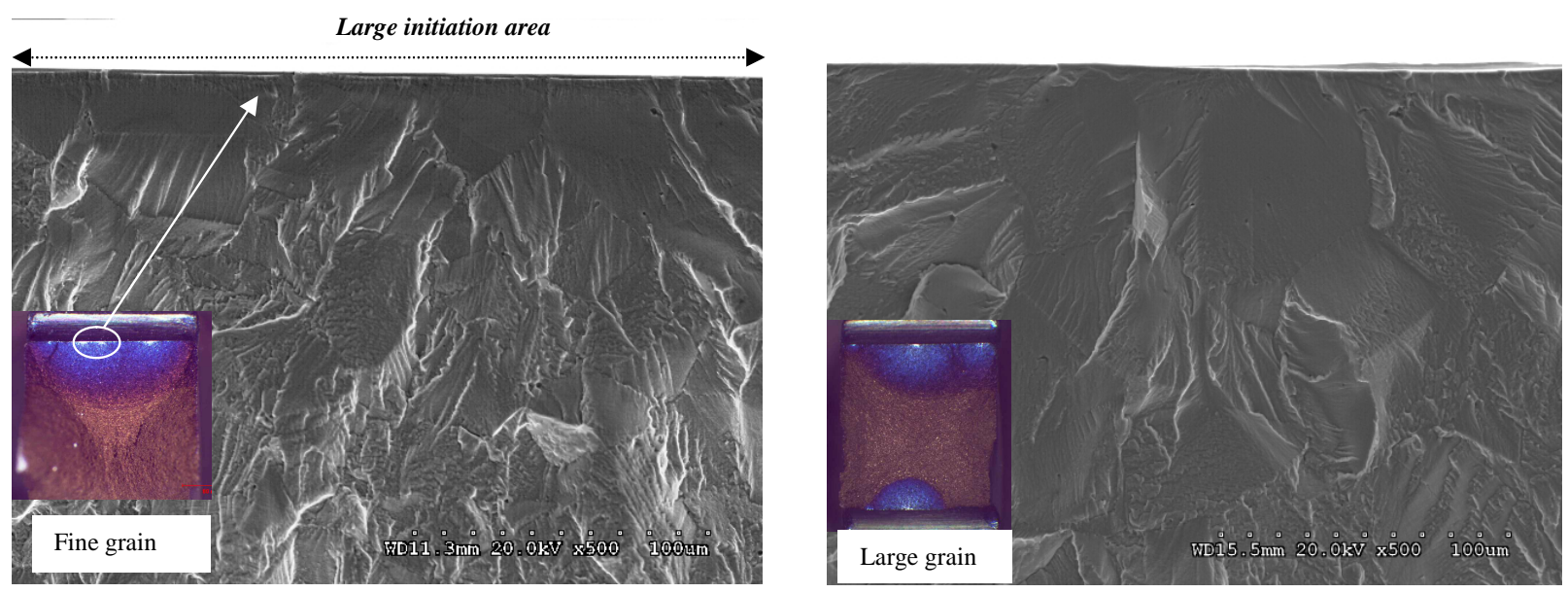

Figure 13. Typical crack surface observed in SEM showing a) multi-sites initiation on specimen machined by mild broaching/fine grain Waspaloy b) large grain initiation/large grain WaspaloyCrack surface macrograph at the corner showing CIS location

The highest lives observed on aggressively machined specimen were observed on the fine grain material and are all associated to crack initiation at sub-surface crystallographic facets (Figure 14a). Actually $50 \%$ of the CIS are in subsurface crystallographic facets. This type of initiations was not observed on low-stress ground and mildly broached specimens. Agressively machined FG material with relatively lower life -but similar to LSG- shows other CIS in either machining defects or deformed grains (Figure 14b) but the propagation from these CIS seem to be delayed. As for LG material, the CIS remains at the surface and starts at large grains (Figure 15a).

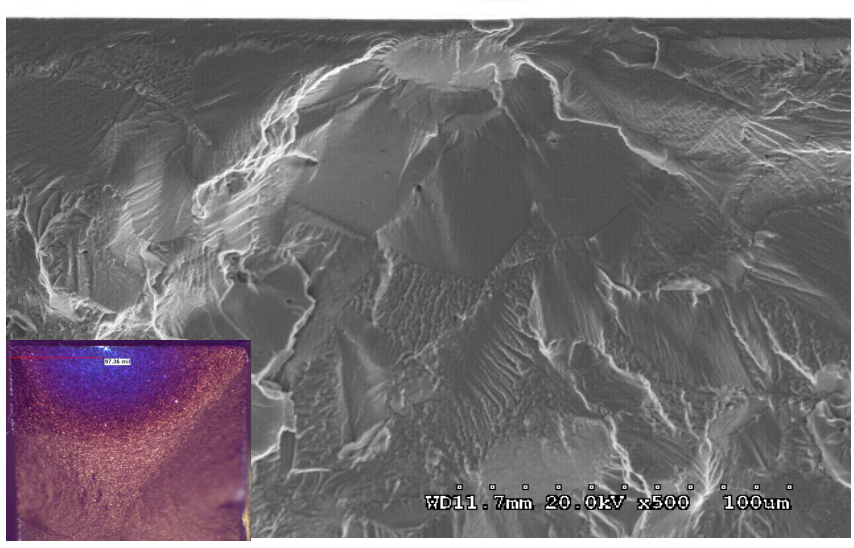

a) CIS in crystallographic facet

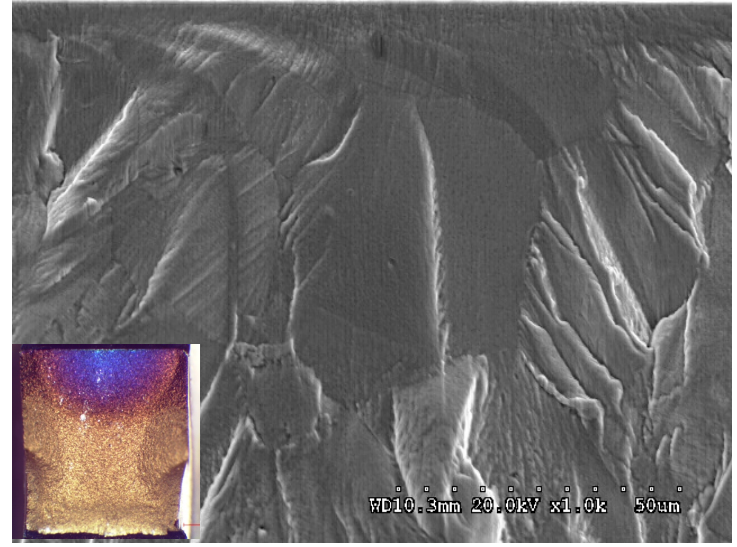

b) CIS in deformed grains grain

Figure 14. Aggressive broaching, SEM observation of CIS in fine grain material, CIS in a) crystallographic facet $b$ ) in deformed grains 
For the very aggressive broaching, microfractography observations show that $50 \%$ of the failures occur at the surface at highly deformed areas and correspond to low lives. The crack initiates in a large area at the surface (Figure 15b). Higher lives were found in specimens where the deformation seems less severe, at surface nicks and inclusions. These features seem to be less harmful than the deformation induced by the very severe broaching.

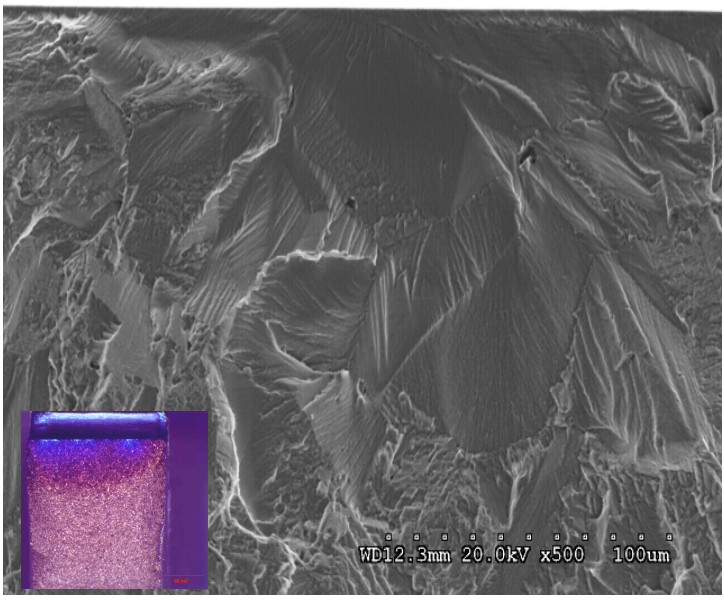

(a)

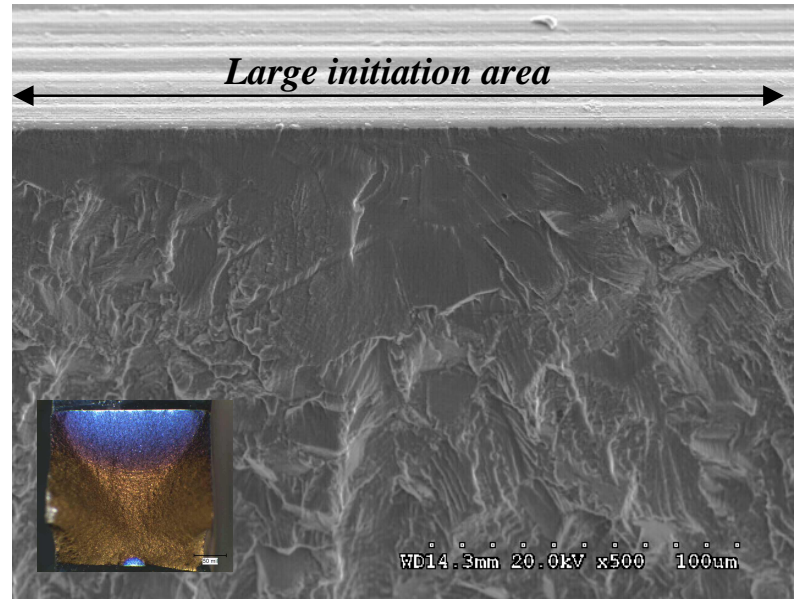

(b)

Figure 15. SEM observation at CIS for a) Aggressive broaching in LG material - CIS in large grains; b) Very aggressive broaching in FG material - Large crack initiation area

Mechanical Properties of the machined surface

To assess the surface changes after machining and understand the decrease of the LCF life after very aggressive machining of the fine grain Waspaloy, nanoindentation measurements were performed at the surface layers and compared with the bulk nanohardness (Table 4).

Table 4. Nano-indentation measurements for FG Waspaloy after very aggressive machining

\begin{tabular}{|l|r|r|r|r|r|r|r|r|}
\cline { 2 - 10 } \multicolumn{1}{c|}{} & \multicolumn{4}{c|}{ Before fatigue } & \multicolumn{4}{c|}{ After fatigue } \\
\cline { 2 - 10 } & \multicolumn{1}{c|}{ Hardness, GPa } & \multicolumn{2}{c|}{ Young Modulus, GPa } & \multicolumn{2}{c|}{ Hardness, GPa } & \multicolumn{2}{c|}{ Young Modulus, GPa } \\
\cline { 2 - 10 } & Average & $\sigma$ & Average & $\sigma$ & Average & $\sigma$ & \multicolumn{1}{c|}{ Average } & \multicolumn{1}{c}{$\sigma$} \\
\hline Very distorted layer & 6.4 & 0.9 & 190 & 6 & 7.6 & 0.6 & 208 & 8 \\
Deformed grain & 6.4 & 1.2 & 207 & 12 & 5.9 & 0.55 & 202 & 13 \\
bulk & 6.3 & 1.1 & 225 & 17 & 6.6 & 0.38 & 215 & 14 \\
\hline
\end{tabular}

* $\sigma:$ Standard deviation

Nano-hardness measurements show that hardness is barely modified by machining. However, Young modulus of the distorted layer is lower than the bulk as well as the deformed layer. After fatigue, the hardness of the distorted layer increases while the underlying deformed layer has softened. The bulk material is slightly hardened probably because of the fatigue cycling. As for the Young modulus E, only the value measured at the distorted layer significantly increases to the bulk material young modulus value. For the deformed underlying layer and the bulk material, E slightly decreases but remains within the error margin of the measurement. 


\section{Discussion}

The two grain sizes studied in this work, ASTM4 $(84 \mu \mathrm{m})$ and ASTM7 $(36 \mu \mathrm{m})$, are within the acceptance criteria of the aerospace industry standard for Waspaloy however their basic fatigue life (LSG), their response to broaching and the subsequent change in fatigue life for the test conditions investigated are noticeably different (Figure 16).

Also, the results are showing that even though the near-surface microstructure is a good indication of the severity of the broaching process, it is not necessarily a good predictor of the resultant LCF life.

Main fatigue crack initiation observed in this work on non-deformed low-stress ground Waspaloy occurred within the larger than average grains. It is thus understandable that compared to the LG, the FG material, for which the probability of presence of large grains is lower, has a better life but a larger scatter.

Some works have shown that crack initiation happens in large grains that are surrounded with grains that have their (111) slip plane at $15^{\circ}$ to those of the large grain. This set of grains is called supergrain [16].

Mild broaching induced at the surface of LG Waspaloy a light deformation enough to create a surface texture that seems to be favorable to retard fatigue initiation, this does not seem to happen for FG Waspaloy.

LG material shows a better life on a probabilistic approach given the tighter scatter in the data. Thus its B0.1 life is almost $60 \%$ higher than FG material while the typical is only $16 \%$ higher. The NSM, however, supports the view that there is no difference between the two grain sizes when the material is machined by mild broaching. This implies that the LG material that has originally lower LCF life recovers from this disadvantage when it is mildly broached.

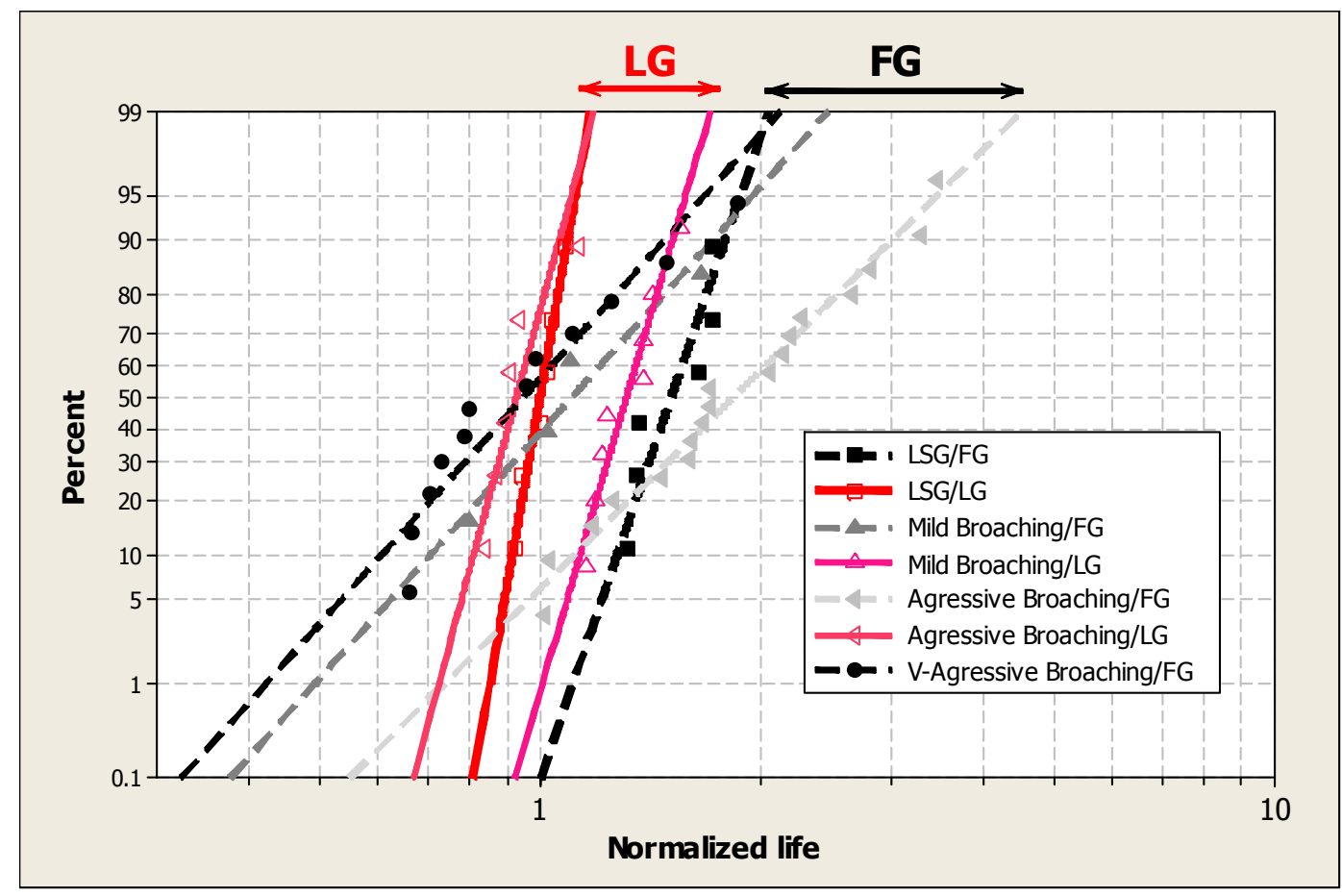

Figure 16. Probability plots comparing fatigue lives for all grain size and machining conditions 
It was shown by other authors that the changes of grain orientation during plastic deformation of Nickel -among other elements- is influenced by the grain size and that a single grain fragments into sub-grains or domains with different orientations [17]. This change in orientation within the large grains is easier than in fine grain and may have eliminated the supergrains making the probability of failure of LG material lower and closer - even better- than the fine grain. This finding has to be confirmed by crystal orientation measurements at the surface; however it certainly explains the life improvement of LG material after a slight deformation induced by mild broaching.

Thus, for this condition, surface finish and machining defects which are usually the most important factors for crack growth initiation on broached surfaces [9] seem to have a lesser effect.

This does not seem to happen when the grain deformation is more severe as for the aggressive broaching. LG Waspaloy loses the ability to delay crack initiation observed after mild broaching, the bad surface condition induced by broaching is then the governing factor for crack initiation. Broaching severity did not seem to have the same effect on FG Waspaloy. As observed in Figure 16, the best B50 life was found for the aggressively broached FG Waspaloy even though showing a very large scatter that is explained by the various CIS found for this condition. However, whatever was the CIS, it was found that the initiation is mainly sub-surface suggesting that the aggressive broaching has induced at the FG surface a strain condition that delays crack initiation. Compressive residual stresses creation at the very surface is the most plausible hypothesis. Even though it is usually claimed that broaching creates near-surface tensile residual stresses [18], it was found that depending on the broaching conditions, compressive residual stresses could be produced [19]. This is what seems to happen in this particular condition with FG Waspaloy. Thus the competition between surface condition after aggressive broaching and surface compressive stresses for impacting fatigue life was won by the compressive stresses like it was shown by other authors on low-alloy steels [20]. The amount of surface work-hardening introduced by the aggressive broaching seems to be what is needed for FG Waspaloy to produce compressive stresses, mild broaching did not provide the sufficient strain to make this happen, but sufficiently to induce grain deformation.

The energy transmitted to the surface by aggressive broaching, was beneficial for FG Waspaloy and not for LG certainly because of its higher yield strength [13, 21].

Above a certain level of plastic deformation induced by broaching, the governing factor for fatigue crack initiation becomes the highly distorted microstructure and its inherent micro and macro-defects as well as its vulnerability to oxidation at elevated temperature [19]. The fatigue life is then reduced by $68 \%$ compared to the sound material. This is what was observed in the FG Waspaloy very aggressively deformed. The surface layer formed by broaching where grain boundaries are not revealed by etching seems to reduce the fatigue crack initiation resistance of the material.

Nanohardness measurements have shown that the severely distorted layer is structurally different and behaves differently from the bulk material as well as the underlying deformed grain layer. It shows a significant hardening that is not observed neither for the bulk material nor the underlying deformed layer which -in the contrary- softens. Its low Young modulus that increases after fatigue cycling at elevated temperature could be an indication that this layer, originally heavily deformed, and thus in a non-equilibrium state, undergoes dynamic recrystallization during fatigue. This behavior is similar to nano-structured $\mathrm{Ni}-\mathrm{Cr}$ alloy material [22] that shows 
hardness increase and short-range ordering when exposed to $400-500^{\circ} \mathrm{C}$. This anomalous behavior cannot explain the low LCF life and leaves the area open for different assumptions.

Thus, further studies to understand the impact of this complex multilayered surface formed by very aggressive broaching on the fatigue behavior of a severely machined Waspaloy surface are needed.

\section{Conclusions}

It can be concluded from this work that same machining conditions could impact differently the fatigue life of Waspaloy depending on its grain size.

1- $\quad$ Fine grain ASTM7 (FG) and large grain ASTM4 (LG) Waspaloy machined properly by low-stress grinding (LSG) exhibit different notch LCF life at elevated temperature and high concentrated stress $\left(593^{\circ} \mathrm{C} / 1793 \mathrm{MPa}\right)$. Main crack initiation sites (CIS) observed are large grains. Thus LG Waspaloy shows lower fatigue life due to its larger grain size and increased probability of "supergrain" presence.

2- $\quad$ Mild broaching compared to LSG improves by $60 \%$ the B0.1 life of LG Waspaloy. Crack initiation always initiates at the surface suggesting that surface compressive stresses could not be the responsible of the observed life improvement. However, fragmenting the grains into domain with different orientations reducing the amount of favorable CIS i.e. "supergrains" could be the reason of life improvement. In contrast, the amount of deformation beneficial to LG has adversely affected FG material life.

3- $\quad$ For aggressive broaching, almost all CIS in FG are subsurface suggesting that the process introduced surface compressive residual stress, which improves the life. However, this did not happen for LG. Surface defects and deformed microstructure became the governing factor for LG material fatigue life

4- Very aggressive broaching reduces by $68 \%$ the fatigue life of the FG Waspaloy due to the formation of a multilayered deformed surface where the grains are no more defined in the top layer. Characteristics of this top layer shows substantial strain hardening during fatigue cycling which needs more studies to be fully understood.

\section{Acknowledgments}

The authors acknowledge support from Pratt \& Whitney Canada in conducting this work, and Mr. Pierre-Yves Lavertu from École Polytechnique de Montréal for metallography work. They are thankful to J. Sapieha and S.Hassani from École Polytechnique de Montréal for the nanoindentation measurements.

\section{References}

1. Choudhury, I.A., El-Baradie, M.A. "Machinability of nickel-based super alloys: a general review", J. Mater. Process. Technol. 77 (1998) p. 278-284.

2. Ezugwu, E.O., Wang, Z.M., Machado, A.R. "Machinability of nickel-based alloys: A review", J. Mater. Process. Technol. 86 (1999) p. 1-16.

3. Arunachalam, R., Mannan, M.A., "Machinability of nickel-based high temperature alloys" Machining Science and Technology, 4 (2000) p. 127-168. 
4. Pawade, R.S., Joshi, S.S., Brahmankar, P.K., Rahman, M., “An investigation of cutting forces and surface damage in high-speed turning of Inconel 718, J. Mater. Process. Technol. 192-193 (2007) p. 139-146.

5. Österle, W., Li, P.X. "Mechanical and thermal responses of a nickel-base superalloy upon grinding with high removal rates", Mater. Science and Engineering A 238 (1997) p. 357366.

6. Lee, S., Hwang, J., Shankar, M.R., Chandrasekar, S., Compton, W.D. "Large Strain Deformation Field in Machining", Metall. Mater. Trans. A, 37A (2006) p. 1633-1643.

7. Swaminathan, S., Shankar, M.R., Rao, B.C., Compton, W.D., Chandrasekar, S., King, A.H., Trumble, K.P., "Severe Plastic Deformation (SPD) and Nanostructured Materials by Machining", J. Mater. Sci. 42 (2007) p. 1529-1541.

8. Sharman, A.R.C., Hughes, J.I., Ridgway, K., "An analysis of the residual stresses generated in Inconel 718 when turning", J. Mater. Process. Technol. 173 (2006) p. 359-367.

9. Connolley, T., Starink, M.J., Reed, P.A.S., "Effect of broaching on high-temperature fatigue behaviour in notched specimens of Inconel 718, Metallurgical an Materials Transactions A, 35A (2004) p.771-783.

10. Qi,H., Jing, X.R., "Surface integrity and its effects on the fatigue life of the nickel-based superalloy GH33A”, Int. J. Fat., 13 (1991) p.322-326.

11. Metallic materials - instrumented indentation test for hardness and materials parameters Part 1: Test method, International Standard ISO 14577-1 (2002).

12. W. C. Oliver, and G.M. Pharr, "An improved technique for determining hardness and elastic modulus using load and displacement sensing indentation experiments," J. Mater. Res,. 7 (1992) p. 1564

13. N. Ben Salah, "Effect of broaching parameters on microstructure and fatigue life of Waspaloy", Pratt \& Whitney Canada Analytical summary report, 2009

14. Y.Xu, L.Fang, Q Cen, J. Zhu, "Nano structure and transformation mechanism of white layer for AISI 1045 steel during impact wear, Wear, 258 (2005) p.537-544

15. Y.B.Guo, J.Sahni, "A comparative study of hard turned and cylindrically ground white layers", International Journal of Machine tools \& Manufacture, 44 (2004) p.135-145

16. D.L. Davidson, R.G.Tryon. M.Oja, R. Matthews, K.S. Ravi Chandran, "Fatigue crack initiation in Waspaloy at $20^{\circ} \mathrm{C}^{\prime}$, Met. And Mat. Transactions A, 38A (2007) p.2214-2225

17. S. Scheriau, R. Pippan, "Influence of grain size on orientation changes during plastic deformation", Mat.Sc. and Eng. A, 493 (2008) p.48-52

18. D. Greving, M.Gorelik, H.Kington "Manufacturing related residual stresses and turbine disk life prediction", Review of quantitative Nondestructive evaluation, vol.24, ed. By D.O.Thompson and D.E.Chimenti (AIP conference proceeding, 2005), p.1339-1346

19. N. Ben Salah, "CPW697 machining process impact on the fatigue life", Pratt \& Whitney Canada internal report, January 2007

20. A. Javidi, U. Rieger, W. Eichlseder, "The ffect of machining on the surface integrity and fatigue life", International Journal of fatigue, 30 (2008) p.2050-2055.

21. M,L,Brogdon "The effect of As-large-as (ALA) grains on the high-temperature fatigue life of Waspaloy" (Report AFRL-ML-WP-TM-2007-4050, AFRL Dayton, 2006)

22. Sh.Mukhtarova, N. Dudova, V.Valitov, "Processing and mechanical properties of bulk nano-strcutured nickel-based alloys", Materials Science and Engineering A, 503 (2009), p.181-184 